\title{
Maternal Undernutrition Alters The Skeletal Muscle Development and Methylation of Myogenic Factors in Progeny: A Randomized Controlled Trial
}

Xiaoling Zhou ( $\sim$ zxldky@126.com )

Tarim University https://orcid.org/0000-0001-6039-5540

\section{Qiongxian Yan}

Institute of Subtropical Agriculture Chinese Academy of Sciences

Liling Liu

Tarim University

\section{Genyuan Chen}

Tarim University

\section{Shaoxun Tang}

Institute of Subtropical Agriculture Chinese Academy of Sciences

\section{Zhixiong He}

Institute of Subtropical Agriculture Chinese Academy of Sciences

\section{Zhiliang Tan}

Institute of Subtropical Agriculture Chinese Academy of Sciences

\section{Research}

Keywords: goat, intrauterine undernutrition, muscle fiber type, myogenic factors, DNA methylation

Posted Date: February 4th, 2021

DOI: https://doi.org/10.21203/rs.3.rs-169185/v1

License: (1) This work is licensed under a Creative Commons Attribution 4.0 International License. Read Full License 


\section{Abstract}

Maternal malnutrition alters protein synthesis and muscle development in offspring. Epigenetic modification is one of the mechanisms involved in this developmental programming. However, the role of the methylation of myogenic factors remains unclear. Twenty-four pregnant goats were assigned to a control $(100 \%$ of the nutrients requirement, $\mathrm{n}=12$ ) or a restricted group ( $60 \%$ of the nutrients requirement, $\mathrm{n}=12)$ between 0.3 and 0.7 gestation $(\mathrm{G})$. Descendants were harvested at $0.7 \mathrm{G}$ and at 91 days after birth to analyze the fiber area and fiber type of femoris muscle and to examine the effects on the mTOR signal pathway and methylation of the promoter regions of myogenic factors. Maternal undernutrition increased the fiber area of the vastus muscle in the fetuses $(P<0.05)$. Undernutrition enhanced $(P<0.01)$ the proportions of $\mathrm{MyHCl}$ and $\mathrm{MyHClIA}$ fibers in the vastus muscle of fetuses and semitendinosus (ST) muscle of kids, while the proportion of MyHCIIX fibers were decreased $(P<0.01)$ in the restricted fetuses and kids. The mRNA expression levels of EYA1 and MYOZ2 in the restricted fetuses were downregulated $(P<0.05)$, but no difference was observed in the restricted kids $(P>0.05)$. The percentage of DNA methylation at the $+530 \mathrm{CpG}$ site of the MYF5 gene in the restricted fetuses was increased $(P<0.05)$, but the methylation percentages of the MYF5 gene at the $+274,280 \mathrm{CpG}$ site and of the MYOD gene at the $+252 \mathrm{CpG}$ site in the restricted kids were reduced $(P<0.05)$. The mTOR protein signals were downregulated $(P<0.05)$ in the restricted fetuses and kids. These results indicated that maternal undernutrition altered the fiber type of femoris muscle in offspring, but its relationship with the methylation in the promoter regions of myogenic genes needs to be further studied.

\section{Background}

During myogenesis, the numbers of myoblast, primary muscle fiber and secondary muscle fiber are determined before birth in humans [1] and domestic animals [2, 3]. The skeletal muscle is highly susceptible to nutritional deficiencies due to the low priority of nutrient acquisition in mammals [4, 5]. Nutritional deficiency in early gestation lessens the number of primary muscle fibers [6], but the effects are generally minor due to low nutrients requirement by early fetuses. Secondary muscle fiber proliferates from around $0.3 \mathrm{G}$ ( $30 \%$ of gestation stage), and this process ceases at about $0.7 \mathrm{G}[1-3]$, which constitutes nearly $95 \%$ of the final fiber population [2]. Insufficient nutrition during midgestation $(0.3-0.7 \mathrm{G})$ affects the number, size, and type of secondary fibers before $[2,7]$ and after birth [8-10]. It is widely accepted that skeletal muscle development is nutritionally programmed in utero $[4,5]$, and understanding the underlying mechanisms of this programming helps to prevent nutritional sarcopenia in humans and improve meat production in livestock.

Alteration of muscle phenotype can partly be interpreted by the changes in hormone response [11], mTOR signaling pathway [7], myogenic regulatory factors expression [12, 13], and mitochondrial function [14] in model animals. However, an unresolved question is how this phenotype is programmed during ontogenetic muscle development. Epigenetic modification is one of the key mechanisms responsible for the persistent programming [15]. Myogenic factors including MYOD, myogenin, MYF5, and MYF6 (or MRF4) govern skeletal muscle determination and differentiation [16], among which MYF5 and MYOD are the master regulators. Epigenetic modification, including DNA methylation of enhancer chromatin [17, 18], histone acetylation, and long noncoding RNA in mice $[19,20]$ of the MYF5 and MYOD genes, is associated with the expression of muscle-specific genes during myogenesis and differentiation. Methylation of the promoter region is a regulation target in intrauterine skeletal programming, for example, the GLUT4 promoter in pigs [21]. However, the relationship 
between methylation of the promoter regions of the Myf5 and MYOD genes and the muscle developmental programming under nutrient stress remains uncharacterized. DNA methylation generally reduces the expression of muscle-related genes [22]. We thus hypothesized that maternal undernutrition during midgestation would decrease the expression of MYF5 and MYOD genes via increasing the methylation of their promoter regions.

Small ruminants are optimum animal models for intrauterine programming [23], and $40 \%$ energy restriction in pregnant goats leads to hepatic metabolic programming in offspring in our previous study [24]. In the present study, we investigated the effects of $40 \%$ maternal undernutrition during mid-gestation on the muscle fiber histology, myosin heavy chain expression, methylation modification of myogenic factors, and the mTOR signal pathway in the skeletal muscles of prenatal and postnatal goats.

\section{Methods}

\section{Ethical approval}

All of the protocols for this study were approved by the Animal Care Committee according to the Animal Care and the Use Guidelines of the Institute of Subtropical Agriculture, the Chinese Academy of Sciences, Changsha, China (No. KYNEAAM-2015-0009).

\section{Experimental design and animal management}

Twenty-four goats ( $45 \pm 3$ d of gestation, Liuyang black goats, a local breed) were selected and tested by portable ultrasonography (Aloka SSD-500 with a 5-MHz linear probe, Aloka, Shanghai, China). Dams were randomly assigned into the control $[100 \%$ of the nutrients requirements suggested in the Chinese Meat Goat Requirements (2004), $n=12$ ] or restricted group ( $60 \%$ of the nutrients requirements, $n=12$ ) according to body weight (BW) and litter size. All dams were placed within individual pens and fed a diet twice ( $0800 \mathrm{~h}$ and 1600 h) per day with a 50:50 ratio of concentrate to roughage, with free access to drinking water. The ingredients and composition of the experimental diet on a dry matter basis are shown in additional Table S1. The feeding of the restricted group was conducted by providing $60 \%$ of the feed allowance of the control group during days 45 100 of gestation, and the actual restriction level $(1.04 \mathrm{~kg} / \mathrm{d}$ for the control group vs $0.62 \mathrm{~kg} / \mathrm{d}$ for the restricted group) was $60.2 \%$ after measurement of the daily feed allowance and refusal. At day 100 of gestation, six pregnant dams per group were selected for harvesting, and ten fetuses (three singlets, two sets of twins, and one set of triplets) in each group were obtained. The ratio of females to males was 7:3 in the control group and 6:4 in the restricted group.

After day 100 of gestation, feed restriction was removed, and the remaining dams were fed to supply $100 \%$ of the nutrients requirements and were managed as before during the following experimental period. After parturition, neonatal kids were nursed by their dams until preweaning between days 50 and 60 . Preweaning was conducted by separating offspring from their dams in the daytime from 0800 to $1600 \mathrm{~h}$, and a mixed diet of starter and fresh Miscanthus spp. was provided at a ratio of 20:80 during this period. Complete weaning was performed on day 60 . Then, all kids were given ad libitum access to the above diet and had free access to drinking water. The ingredients and composition of the kid diet are shown in a Table S1. At 90 days of age, eight kids in each group were obtained for harvesting. The ratio of females to males was 3:5 in the control and 4:4 in the restricted group. 


\section{Body weight measurement and muscle tissue sampling}

At day 100 of gestation and at day 90 after birth, the feeding of all selected animals was withdrawn for $24 \mathrm{~h}$, while clear water was offered freely. The empty BW of fetuses and kids were reported previously [24]. Following electric shock and exsanguination, samples of semitendinosus (ST) and vastus lateralis (VL) muscle were collected from the kids, while the gross vastus muscle in the fetuses was sampled because it was difficult to dissect into individual muscles. The sliced tissue samples were immersed in $10 \%$ formalin fixing solution for histology measurement, while another aliquot of samples was quick-frozen in liquid nitrogen and then stored at $-80^{\circ} \mathrm{C}$ for further analysis.

\section{Histology}

After fixation, the muscle samples were embedded in paraffin, sliced at a thickness of $8 \mu \mathrm{m}$ using a rotary microtome (RM2016, Leica Microsystems Inc., Wetzlar, Germany), and stained with hematoxylin (AS1055A, Aspen Biological, Inc., Wuhan, China) and eosin (AS1094, Aspen Biological, Inc.) according to Zou et al. [12]. Ten different microscopic fields of each section and five sections per sample were randomly chosen to determine the muscle fiber area using the Image Pro Plus 6.0 software (Media Cybernetics, Bethesda, USA).

\section{Quantitative real-time PCR}

The extraction and qualification of total RNA and the analyses of messenger RNA (mRNA) expression levels were performed using the SYBR green-based method with gene-specific primers (Table 1) according to Zhou et al. [24]. A melt curve analysis was conducted to confirm specific product amplification. ACTG1 was used as the reference gene, and the real-time PCR data were calculated using the $2^{-\Delta \Delta C t}$ method [25]. The expression of mRNA was presented as the fold change relative to the reference gene.

\section{Immunoblotting analysis}

The extraction and qualification of total protein and the immunoblotting analysis were carried out according to the method described [26]. The primary antibodies of MyHCl (MYH7, No. MFCD00162703, Merck KGaA, Darmstadt, Germany), MyHC-Ila (MYH2, No. ab124937, Abcam plc. Cambridge, USA), MyHC-Ilx (No. BM0096, Boster Biological Technology Co. Ltd, California, USA), and $\beta$-tubulin (No. 2146S, Cell Signaling Technology, Inc., Danvers, UK) were diluted according to 1:5000, 1:10000, 1:100 and 1:1000, respectively. The primary antibodies of AKT (No. AV06008-100UL, Merck KGaA, Darmstadt, Germany), p-AKT (No. 9275, Cell Signaling Technology, Inc., Danvers, MA, USA), PI3K (No. C312573, LifeSpan BioSciences, Inc., Seattle, WA, USA), p-PI3K (No. C358831, LifeSpan BioSciences, Inc.), mTOR (No. PLA0114, Merck KGaA), p-mTOR (No. 2971, Cell Signaling Technology, Inc.), and $\beta$-Actin (No. 4976, Cell Signaling Technology, Inc.) were diluted as 1/1000. The density of bands was quantified and then normalized to the reference protein of $\beta$-tubulin or $\beta$-Actin. The normalized values were used for comparison of the relative expression levels of the target proteins between the control group and the restricted group.

\section{DNA methylation detection}

Approximately $20 \mathrm{mg}$ of frozen sample was ground in liquid nitrogen, and DNA was extracted using a DNeasy Blood \& Tissue Kit (Qiagen, Hilden, Germany) according to the manufacturer's instructions. The quantitative 
methylation analysis of multiple CpG sites was performed by the Beijing Genomics Institute (Guanzhou, China) using a Sequenom EpiTYPE system based on MALDI-TOF mass spectrometry according to Suchiman et al. [27]. The CpG-rich sequences for MYF5 and MYOD were selected using EMBOSS Cpgplot

(https://www.ebi.ac.uk/Tools/seqstats/emboss_cpgplot/), and one CpG island was found in the primer regions of MYF5 and MYOD. The CpG island of MYF5 ranges from the site of -10 to +347 bp relative to the TSS site (10070240 - 10070597 in chromosome 5). The forward primer sequence of MYF5 was

TTTATTTTGGGTAGTTTTTGGTTAGG tagged with the T7-promoter of aggaagagag, while the reverse sequence was CCCAAAAATATATAAAAAACCCCAA tagged with the sequence of cagtaatacgactcactatagggagaaggct. The product size was $558 \mathrm{bp}$ from -44 to +503 (10070196 to 10070753 in chromosome 5) and covered $41 \mathrm{CpG}$ sites, among which $34 \mathrm{CpGs}$ could be effectively quantified. The $\mathrm{CpG}$ island of MYOD ranges from the site of +159 to +888 relative to the TSS site (47532862 to 47533591 in chromosome 15). The forward primer sequence of MYOD was TAGTTTTGGGAGTTTAGTGTGAAGG tagged with the T7-promoter of aggaagagag, while the reverse sequence was CCTTACAAACCCACAATAAACAA tagged with cagtaatacgactcactatagggagaaggct. The product size was 546 bp from -15 to $+530(47532688-47533233$ in chromosome 15) and covered $55 \mathrm{CpG}$ sites, among which $42 \mathrm{CpGs}$ could be effectively quantified. The spectral data were pre-processed and analyzed according to the method of Suchiman et al. [27]. The methylation level of the restricted group in each $\mathrm{CpG}$ site was expressed as the value relative to the control group.

\section{Statistical analysis}

Data were analyzed by a mixed model with treatment, gender and litter size as fixed factors, and initial BW of dams as the covariate. Statistical significance was considered at $P<0.05$, and Sidak method was applied to compare means. All results are presented as the means and standard errors (SE).

\section{Results}

\section{Body weight (BW) and area of muscle fibers}

The effect of maternal undernutrition on the muscle fiber area of fetuses and kids is presented in Fig. 1. The BW of fetuses were unaffected $(P>0.05)$ by undernutrition, but the BW of restricted kids was decreased relative to controls $(P=0.027)$. The muscle fiber area of the vastus muscle of restricted fetuses was increased $(P=0.032)$, while it was unaffected $(P>0.05)$ in the ST and VL muscles of restricted kids. Gender and litter size did not affect the area of muscle fibers in the fetuses or kids $(P>0.05)$.

\section{Myosin heavy chain expression}

The effect of maternal undernutrition on the expression of myosin heavy chain in the muscle tissues of fetuses and kids is presented in Fig. 2. The expression of MyHCIIB mRNA in the fetuses and kids was not detectable, so the expression of MyHCIIB protein in these samples was not analyzed further. Compared to the control group, maternal undernutrition did not change $(P>0.05)$ the expression of $\mathrm{MyHCl}, \mathrm{MyHCIIA}$, or MyHCIIX mRNA in the vastus muscles of fetuses (Fig. 2A), or in the ST (Fig. 2B) and VL (Fig. 2C) muscles of kids. However, the protein expression levels of $\mathrm{MyHCl}$ and $\mathrm{MyHCllA}$ were increased $(P<0.05)$ both in the vastus muscles of fetuses (Fig. 2D) and in the ST muscles of kids (Fig. 2E), while the MyHCIIX protein expression in the fetuses and in the ST muscles of kids was decreased $(P<0.01)$. Protein expression levels of $\mathrm{MyHCl}, \mathrm{MyHClIA}$, and $\mathrm{MyHCIIX}$ in the $\mathrm{VL}$ 
muscles of kids (Fig. 2F) were not affected $(P>0.05)$. Gender and litter size did not affect $(P>0.05)$ the mRNA or protein expression of $\mathrm{MyHCl}, \mathrm{MyHCIIA}$, and $\mathrm{MyHCIIX}$ genes in the fetuses or kids.

\section{mRNA expression and DNA methylation of myogenic factors}

Since no significant differences in myosin heavy chain expression of muscle resulting from maternal undernutrition were observed, we further determined the mRNA expression and DNA methylation of myogenic factors in the muscles of fetuses and kids (Fig. 3). Maternal undernutrition did not influence $(P>0.05)$ the expression of MYF5, MYF6, MYOD, or MYOG mRNA in the vastus muscles of fetuses (Fig. 3A) or in the ST muscles of kids (Fig. 3B). The expression levels of EYA1 $(P=0.044)$ and $\operatorname{MYOZ2}(P=0.038)$ mRNA in the vastus muscles of restricted fetuses were downregulated, while no difference was observed in the ST muscles of kids $(P>0.05)$. Maternal undernutrition increased $(P=0.040)$ the methylation level of $+530 \mathrm{CpG}$ site of MYOD gene in the fetuses, while the methylation levels of the $+274,280 \mathrm{CpG}$ site of the MYF5 gene and the $+252 \mathrm{CpG}$ site of the MYOD gene in the restricted kids were decreased $(P<0.05)$. The methylation levels of the remaining CpG sites of MYOD and MYF5 genes were not affected $(P>0.05)$ in the fetuses or kids. Gender and litter size did not affect $(P>0.05)$ the mRNA expression of these genes or the CpG methylation of MYF5 and MYOD promoters in the fetuses. Gender affected $(P<0.05)$ the MYF5 and SIX1 mRNA expression in kids, which were greater in the females than that in the males. And the methylation of the MYF5+32 CpG site in the female kids was higher $(P=0.041)$ than that of the males.

\section{mTOR Signaling Pathway}

Maternal undernutrition reduced $(P<0.01)$ the protein expression of mTOR, p-mTOR, and the ratio of $\mathrm{p}$ $\mathrm{mTOR} / \mathrm{mTOR}$ in fetal vastus muscle. Maternal undernutrition also reduced $(P=0.037)$ the mTOR protein expression in kids and tended to reduce $(P=0.088)$ the PI3K phosphorylation level, while the effects on the PI3K, AKT, and p-AKT proteins and the ratio of p-AKT/AKT in kids were not significant $(P>0.05)$. Gender and litter size did not affect the above protein expression in the fetuses or kids $(P>0.05)$.

\section{Discussion}

During the past two decades, there has been increased research interest in the effect of maternal undernutrition on muscle development of offspring. In this study, maternal undernutrition altered the muscle fibers and composition of the vastus muscle in fetuses and kids, and downregulated the mRNA expression of myogenic factors in the fetuses. DNA methylation levels of several sites in the MYF5 and MYOD promoter regions in the fetuses and kids were also affected by maternal undernutrition. Many studies have confirmed that maternal undernutrition in the second trimester is closely associated with the thrifty phenotype of offspring in human epidemiological surveys $[28,29]$ and in animal model trials $[8,30,31]$. In the present study, no changes in the BW of fetuses and the diminished BW in the restricted kids were consistent with a compensation effect by the mother in utero and a thrifty phenotype after birth. However, the increment of muscle fiber area in restricted fetuses in this study was not consistent with the findings (no significant change) in the fetuses of cattle [13] and pigs [12] during midgestation or in sheep (the decreased size) [7]. According to Wigmore and Stickland [2], the primary fibers begin to lose the central myofibril-free region at around $0.65 \mathrm{G}$, and then the diameter of the muscle fibers decreases rapidly. The nutrient-restricted fetuses can prolong the maturation of the primary muscle fibers and delay the time of disappearance of the central myofibril-free cytoplasm. In this study, the 
observation period of fetal muscle fibers coincided with this stage $(0.67 \mathrm{G})$, and this may be the reason for the increase in the area of muscle fibers of the restricted fetuses.

Skeletal muscle is generally divided into four types according to myosin heavy chains (MyHC): slow-twitched type I (MyHCl), fast-twitched type IIA (MyHCIIA), IIB (MyHCIIB), and IIX (MyHCIIX). Previously, Zhu et al. [10] reported that $50 \%$ maternal undernutrition increased the MyHCIIB ratio and decreased the percentage of MyHCIIA of the longissimus dorsi (LD) muscle in the restricted lambs at eight months of age, while the type composition of LD and ST muscles in the $50 \%$ restricted lambs at 150 days of age was unaffected [8]. In contrast, Fahey et al. [32] reported fewer fast fibers and more slow fibers in the LD and VL muscles of $50 \%$ maternally restricted 14-day-old lambs. In this study, the types of $\mathrm{MyHCl}$ and $\mathrm{MyHClIA}$ were increased, but $\mathrm{MyHCIIX}$ was decreased both in the vastus muscle of $40 \%$ restricted fetuses and in the ST muscles of restricted kids, while the VL muscles in offspring were not affected. These results suggest that the effects of similar maternal undernutrition during midgestation on the muscle fiber development vary, and the cause needs further research. Moreover, comparing LD and ST fibers from the same muscle position, a similar degree of feeding restriction (such as $50 \%$ ) exerted different effects on muscle fiber development $[8,10,32]$. It has been speculated that this discrepancy is related not only to the muscle fiber composition in different muscle positions but also to the timing of phenotypic plasticity induced by different types of nutrient restriction [33,34].

In this study, we noted an inconsistency in the expression between mRNA and protein levels of MyHC isoforms in the fetal vastus and kid ST muscles. Similar differences in mRNA and protein abundances of MyHC genes have been reported in other species [35]. Generally, the protein accretion rate of hindlimb muscle is approximately $0.17 \%$ per day in ovine fetuses [36] and $0.8 \%$ in young lambs [37]. However, transcriptional and posttranscriptional regulation of $\mathrm{MyHC}$ isoforms mRNA in muscle tissue is active and sensitive to environmental cues (e.g., hormones or metabolites) [38, 39]. MyHC expression at the protein level represents the existing fiber type composition within the muscle. Therefore, the effect of protein expression was highlighted.

Consistent changes in the MyHC types in the vastus muscle and the ST muscle of the goats hinted that metabolic programming could have taken place in the present study. DNA methylation is one of the universal mechanisms regulating this phenotypic change [40]. MYF5 and MYOD gene methylation is important in regulating muscle differentiation. Increased methylation of three important $\mathrm{CpG}$ sites in the MYOD1 gene and decreased MYOD1 mRNA expression have been observed during the differentiation of human primary muscle fibers from myoblasts to myotubes, while the methylation and mRNA levels of the MYF5 gene were decreased [41]. However, there are few reports on the methylation modification of these two MRF factors under intrauterine nutrition restriction. Our results revealed that maternal nutritional restriction during midgestation affected the methylation of individual sites in the MYOD and MYF5 promoter regions of the fetuses and kids. These affected sites may not be closely correlated with the regulation of MYOD and MYF5 mRNA expression, because the mRNA expression of MYOD and MYF5 was unaffected. Previous studies have shown that maternal low-amino acid diets in the middle and late stages of pregnancy reduced the methylation level of the CpG island in IGF2R gene intron 2 in the longissimus muscles of sheep fetuses at 130 days [42]. A similar study found that the average $\mathrm{CpG}$ island methylation in the $P G C 1 A$ promoter sequence in the skeletal muscle of introuterine growth retardation rats with protein restriction during pregnancy increased, while the GLUT4 and PGC1A mRNA expression and glucose tolerance decreased [43]. In our study, we have not yet identified the key methylation modification sites that can explain the phenotypic changes in offspring, thus further research is needed. 
The mRNA expression levels of myogenic factors MYOG and MRF4 in fetuses and kids were unaffected, but the levels of EYA1 and MYOZ1 mRNA were decreased in the restricted fetuses. SIX and EYA1 genes are specifically involved in the differentiation of limb buds [44]. The SIX1 and EYA1 proteins accumulate preferentially in the nuclei of fast-twitch muscles and induce a fiber-type transition with the replacement of myosin heavy chain I and IIA isoforms by the faster IIB and/or IIX isoforms [45]. Furthermore, MYOZ2 is expressed in slow-twitch skeletal muscle, and the downregulation of MYOZ2 is associated with increased slow-twitch muscle fibers [46]. The downregulation of EYA1 and MYOZ2 mRNA in the restricted fetuses is consistent with the increases in $\mathrm{MyHCl}$ and MyHCIIA types and the decrease in MyHCIIx in the present study.

The development of skeletal muscle is a highly complicated process involving nutritional factors and numerous signaling pathways to regulate muscle-specific transcription factors, and mTOR signaling is a key regulator of skeletal muscle development at distinct stages of myogenesis [47]. In this study, mTOR protein was downregulated in the femoris muscles of fetuses and kids. We considered that compared to the normal energy requirement, a $40 \%$ maternal undernutrition aggravated the overall lack of proteins and amino acids, resulting in the downregulation of the mTOR signals in the offspring, thereby affecting the protein synthesis of muscle tissues. Furthermore, the mTOR protein controls the muscle-specific miR-1 transcription in mice that regulates the stability of MYOD and MYF5 expression [48]. In addition, other miRNAs such as miR-133, miR-206, and miR125b are also linked to the mTOR pathway to regulate muscle fiber differentiation $[48,49]$, and the musclespecific expression of miRNAs can be regulated by nutrients through epigenetic mechanisms [47]. This provides new ideas for studying the mechanism of muscle fiber development programming under maternal nutrition restriction.

\section{Conclusion}

The maternal undernutrition during midgestation increased the expression of $\mathrm{MyHCl}$ and $\mathrm{MyHClIA}$ proteins in the vastus muscles of fetuses and the ST muscles of kids and reduced MyHCIIX protein expression, hinting at the developmental programming of skeletal muscle fibers. Transcripts of EYA1 and MYOZ2 genes in the restricted fetuses were downregulated, and the mTOR protein signals declined in the restricted fetuses and kids. Maternal feeding restriction may prompt the switch from $\mathrm{MyHCIIX}$ to $\mathrm{MyHCl}$ and IIA in the femoris muscles of fetuses and kids associated with repression of the mTOR pathway. This programming was associated with the reduction of EYA1 and MYOZ2 transcripts, but the association between the mRNA expression and the DNA methylation in the promoter region of the myogenic factors MYF5 and MYOD needs to be further investigated.

\section{Abbreviations}

$\mathrm{MyHCl}=$ myosin heavy chain 1; MyHCIIA = myosin heavy chain IIA; MyHCIX = myosin heavy chain IIX; MYF5 = myogenic factor 5; MYF6 = myogenic factor 6; MYOD = myogenic differentiation 1; MYOG = myogenin, EYA1 = eyes absent homolog 1; SIX 1 = homeobox protein SIX1; MYOZ1 = myozenin 1; MYOZ2 = myozenin 2; GLUT4 = glucose transporter type 4 .

\section{Declarations}

\section{Ethics approval and consent to participate}


All of the protocols for this study were approved by the Animal Care Committee according to the Animal Care and the Use Guidelines of the Institute of Subtropical Agriculture, the Chinese Academy of Sciences, Changsha, China (No. KYNEAAM-2015-0009).

\section{Consent for publication}

Not applicable.

\section{Availability of data and materials}

All data generated or analysed during this study are included in this published article and its supplementary information files.

\section{Competing interests}

The authors declare that they have no competing interests.

\section{Funding}

This work was supported by the National Natural Science Foundation of China [31760678, 31730092 and 31402105]; State Key Project of Research and Development Plan [2018YFD0501900]; and Hunan innovative Province construction project [2019RS3021].

\section{Authors' contributions}

XZ: Investigation, Data collection, Writing; QY: Project administration, ConceptualizationखInvestigation; LL: Data Curation; GC: Data collection; ST: Data analysis; ZH: Visualization; ZT: Conceptualization, Funding acquisition. All authors read and approved the final manuscript.

\section{Acknowledgements}

Not applicable.

\section{Authors' information}

Email addresses of all authors: Xiaoling Zhou, zxldky@126.com; Qiongxian Yan, yanqx14@isa.ac.cn; Liling Liu, III.net@163.com; Genyuan Chen, 149957871@qq.com; Shaoxun Tang, shaoxuntang@163.com; Zhixiong He, zxhe@isa.ac.cn; Zhiliang Tan, zltan@isa.ac.cn. Full postal address of the submitting author: Institute of Subtropical Agriculture, Yuanda 2nd Road 644\#, Furong District, Changsha P.O. Box 10\#, Hunan 410125, P.R. China.

\section{References}

1. Marini M, Manetti M, Rosa I, Ibba-Manneschi L, Sgambati E. Telocytes in human fetal skeletal muscle interstitium during early myogenesis. Acta Histochem 2018;120(5):397-404. doi: https://doi.org/10.1016/j.acthis.2018.04.003. 
2. Wigmore PM, Stickland NC. Muscle development in large and small pig fetuses. J Anat 1983;137 (Pt 2):23545.

3. Fahey AJ, Brameld JM, Parr T, Buttery PJ. Otogeny of factors associated with proliferation and differentiation of muscle in the ovine fetus. J Anim Sci 2005;83(10):2330-8.

4. Sharples AP, Stewart CE, Seaborne RA. Does skeletal muscle have an 'epi'-memory? The role of epigenetics in nutritional programming, metabolic disease, aging and exercise. Aging Cell 2016;15(4):603-16. doi: 10.1111/acel.12486.

5. Du M, Wang B, Fu X, Yang Q, Zhu MJ. Fetal programming in meat production. Meat Sci 2015;109:40-7. doi: 10.1016/j.meatsci.2015.04.010.

6. Ward SS, Stickland NC. Why are slow and fast muscles differentially affected during prenatal undernutrition? Muscle Nerve 1991;14(3):259-67. doi: 10.1002/mus.880140310.

7. Zhu MJ, Ford SP, Nathanielsz PW, Du M. Effect of maternal nutrient restriction in sheep on the development of fetal skeletal muscle. Biol Reprod 2004;71(6):1968-73. doi: 10.1095/biolreprod.104.034561.

8. Sen U, Sirin E, Ensoy U, Aksoy Y, Ulutas Z, Kuran M. The effect of maternal nutrition level during midgestation on postnatal muscle fibre composition and meat quality in lambs. Anim Prod Sci 2016;56(5):83443. doi: 10.1071/An14663.

9. Mohrhauser DA, Taylor AR, Gonda MG, Underwood KR, Pritchard RH, Wertz-Lutz AE, Blair AD. The influence of maternal energy status during mid-gestation on beef offspring tenderness, muscle characteristics, and gene expression. Meat Sci 2015;110:201-11. doi: 10.1016/j.meatsci.2015.07.017.

10. Zhu MJ, Ford SP, Means WJ, Hess BW, Nathanielsz PW, Du M. Maternal nutrient restriction affects properties of skeletal muscle in offspring. J Physiol 2006;575(Pt 1):241-50. doi:

10.1113/jphysiol.2006.112110.

11. Ford SP, Hess BW, Schwope MM, Nijland MJ, Gilbert JS, Vonnahme KA, Means WJ, Han H, Nathanielsz PW. Maternal undernutrition during early to mid-gestation in the ewe results in altered growth, adiposity, and glucose tolerance in male offspring. J Anim Sci 2007;85(5):1285-94. doi: 10.2527/jas.2005-624.

12. Zou T, He D, Yu B, Yu J, Mao X, Zheng P, He J, Huang Z, Chen D. Moderate Maternal Energy Restriction During Gestation in Pigs Attenuates Fetal Skeletal Muscle Development Through Changing Myogenic Gene Expression and Myofiber Characteristics. Reprod Sci 2016;24(1):156-67. doi: 10.1177/1933719116651151.

13. Jennings TD, Gonda MG, Underwood KR, Wertz-Lutz AE, Blair AD. The influence of maternal nutrition on expression of genes responsible for adipogenesis and myogenesis in the bovine fetus. Animal 2016;10(10):1697-705. doi: 10.1017/S1751731116000665.

14. Zou T, Yu B, Yu J, Mao X, Zheng P, He J, Huang Z, Liu Y, Chen D. Moderately decreased maternal dietary energy intake during pregnancy reduces fetal skeletal muscle mitochondrial biogenesis in the pigs. Genes Nutr 2016;11:19. doi: 10.1186/s12263-016-0535-1.

15. Laker RC, Ryall JG. DNA Methylation in Skeletal Muscle Stem Cell Specification, Proliferation, and Differentiation. Stem Cells Int 2016;2016:5725927. doi: 10.1155/2016/5725927.

16. Braun T, Gautel M. Transcriptional mechanisms regulating skeletal muscle differentiation, growth and homeostasis. Nat Rev Mol Cell Biol 2011;12(6):349-61. doi: 10.1038/nrm3118.

17. Chandra S, Terragni J, Zhang G, Pradhan S, Haushka S, Johnston D, Baribault C, Lacey M, Ehrlich M. Tissuespecific epigenetics in gene neighborhoods: myogenic transcription factor genes. Hum Mol Genet 
2015;24(16):4660-73. doi: 10.1093/hmg/ddv198.

18. Ehrlich KC, Paterson HL, Lacey M, Ehrlich M. DNA Hypomethylation in Intragenic and Intergenic Enhancer Chromatin of Muscle-Specific Genes Usually Correlates with their Expression. Yale J Biol Med 2016;89(4):441-55.

19. Yu X, Zhang Y, Li T, Ma Z, Jia H, Chen Q, Zhao Y, Zhai L, Zhong R, Li C, et al. Long non-coding RNA Linc-RAM enhances myogenic differentiation by interacting with MyoD. Nature communications 2017;8:14016. doi: 10.1038/ncomms14016.

20. Cichewicz MA, Kiran M, Przanowska RK, Sobierajska E, Shibata Y, Dutta A. MUNC, an Enhancer RNA Upstream from the MYOD Gene, Induces a Subgroup of Myogenic Transcripts in trans Independently of MyoD. Mol Cell Biol 2018;38(20):e00655-17. doi: 10.1128/MCB.00655-17.

21. Wang J, Cao M, Yang M, Lin Y, Che L, Fang Z, Xu S, Feng B, Li J, Wu D. Intra-uterine undernutrition amplifies age-associated glucose intolerance in pigs via altered DNA methylation at muscle GLUT4 promoter. Br J Nutr 2016;116(3):390-401. doi: 10.1017/s0007114516002166.

22. Miyata K, Miyata T, Nakabayashi K, Okamura K, Naito M, Kawai T, Takada S, Kato K, Miyamoto S, Hata K, et al. DNA methylation analysis of human myoblasts during in vitro myogenic differentiation: de novo methylation of promoters of muscle-related genes and its involvement in transcriptional down-regulation. Hum Mol Genet 2015;24(2):410-23. doi: 10.1093/hmg/ddu457.

23. Symonds ME, Budge $\mathrm{H}$. Nutritional models of the developmental programming of adult health and disease: Workshop on 'Nutritional models of the developmental origins of adult health and disease'. Proc Nutr Soc 2009;68(2):173-8. doi: 10.1017/S0029665109001049.

24. Zhou X, Yang H, Yan Q, Ren A, Kong Z, Tang S, Han X, Tan Z, Salem AZM. Evidence for liver energy metabolism programming in offspring subjected to intrauterine undernutrition during midgestation. Nutr Metab (Lond) 2019;16(1):20. doi: 10.1186/s12986-019-0346-7.

25. Livak KJ, Schmittgen TD. Analysis of relative gene expression data using real-time quantitative PCR and the 2- $\Delta \Delta$ CT method. Methods 2001;25(4):402-8. doi: doi.org/10.1006/meth.2001.1262.

26. Chen W, Yan Q, Yang H, Zhou X, Tan Z. Effects of restrictions on maternal feed intake on the immune indexes of umbilical cord blood and liver Toll-like receptor signaling pathways in fetal goats during pregnancy. Journal of Animal Science and Biotechnology 2019;10(1):29. doi: 10.1186/s40104-019-0336-7.

27. Suchiman HED, Slieker RC, Kremer D, Slagboom PE, Heijmans BT, Tobi EW. Design, measurement and processing of region-specific DNA methylation assays: the mass spectrometry-based method EpiTYPER. Frontiers in genetics 2015;6:287. doi: 10.3389/fgene.2015.00287.

28. Strauss RS, Dietz WH. Low maternal weight gain in the second or third trimester increases the risk for intrauterine growth retardation. J Nutr 1999;129(5):988-93. doi: 10.1093/jn/129.5.988.

29. Retnakaran R, Wen SW, Tan H, Zhou S, Ye C, Shen M, Smith GN, Walker MC. Association of Timing of Weight Gain in Pregnancy With Infant Birth Weight. JAMA pediatrics 2018;172(2):136-42. doi: 10.1001/jamapediatrics.2017.4016.

30. Mohrhauser DA, Taylor AR, Underwood KR, Pritchard RH, Wertz-Lutz AE, Blair AD. The influence of maternal energy status during midgestation on beef offspring carcass characteristics and meat quality. J Anim Sci 2015;93(2):786-93. doi: 10.2527/jas.2014-8567. 
31. Piaggio L, Quintans G, San Julian R, Ferreira G, Ithurralde J, Fierro S, Pereira ASC, Baldi F, Banchero GE. Growth, meat and feed efficiency traits of lambs born to ewes submitted to energy restriction during midgestation. Animal 2018;12(2):256-64. doi: 10.1017/S1751731117001550.

32. Fahey AJ, Brameld JM, Parr T, Buttery PJ. The effect of maternal undernutrition before muscle differentiation on the muscle fiber development of the newborn lamb. J Anim Sci 2005;83(11):2564-71. doi: $10.2527 / 2005.83112564 x$.

33. Hartman S, Belsky J. Prenatal stress and enhanced developmental plasticity. J Neural Transm (Vienna) 2018;125(12):1759-79. doi: 10.1007/s00702-018-1926-9.

34. Wells JCK. Developmental plasticity as adaptation: adjusting to the external environment under the imprint of maternal capital. Philosophical transactions of the Royal Society of London Series B, Biological sciences 2019;374(1770):20180122. doi: 10.1098/rstb.2018.0122.

35. Sun X, Liu Z, Wu B, Zhou L, Wang Q, Wu W, Yang A. Differences between fast and slow muscles in scallops revealed through proteomics and transcriptomics. BMC Genomics 2018;19(1):377. doi: 10.1186/s12864018-4770-2.

36. Rozance PJ, Zastoupil L, Wesolowski SR, Goldstrohm DA, Strahan B, Cree-Green M, Sheffield-Moore M, Meschia G, Hay WW, Wilkening RB, et al. Skeletal muscle protein accretion rates and hindlimb growth are reduced in late gestation intrauterine growth-restricted fetal sheep. The Journal of physiology 2018;596(1):67-82. doi: 10.1113/jp275230.

37. Claeys MC, Mulvaney DR, McCarthy FD, Gore MT, Marple DN, Sartin JL. Skeletal muscle protein synthesis and growth hormone secretion in young lambs treated with clenbuterol. J Anim Sci 1989;67(9):2245-54.

38. Danzi S, Klein I. Posttranscriptional regulation of myosin heavy chain expression in the heart by triiodothyronine. Am J Physiol Heart Circ Physiol 2005;288(2):H455-60. doi: 10.1152/ajpheart.00896.2004.

39. Zhang D, Wang X, Li Y, Zhao L, Lu M, Yao X, Xia H, Wang YC, Liu MF, Jiang J, et al. Thyroid hormone regulates muscle fiber type conversion via miR-133a1. J Cell Biol 2014;207(6):753-66. doi: 10.1083/jcb.201406068.

40. Carrio E, Diez-Villanueva A, Lois S, Mallona I, Cases I, Forn M, Peinado MA, Suelves M. Deconstruction of DNA methylation patterns during myogenesis reveals specific epigenetic events in the establishment of the skeletal muscle lineage. Stem Cells 2015;33(6):2025-36. doi: 10.1002/stem.1998.

41. Davegårdh C, Broholm C, Perfilyev A, Henriksen T, García-Calzón S, Peijs L, Hansen NS, Volkov P, Kjøbsted R, Wojtaszewski JFP, et al. Abnormal epigenetic changes during differentiation of human skeletal muscle stem cells from obese subjects. BMC Med 2017;15(1):39. doi: 10.1186/s12916-017-0792-x.

42. Lan X, Cretney EC, Kropp J, Khateeb K, Berg MA, Peñagaricano F, Magness R, Radunz AE, Khatib H. Maternal Diet during Pregnancy Induces Gene Expression and DNA Methylation Changes in Fetal Tissues in Sheep. Frontiers in genetics 2013;4:49. doi: 10.3389/fgene.2013.00049.

43. Zeng Y, Gu P, Liu K, Huang P. Maternal protein restriction in rats leads to reduced PGC-1a expression via altered DNA methylation in skeletal muscle. Mol Med Report 2013;7(1):306-12. doi:

10.3892/mmr.2012.1134.

44. Fougerousse F, Durand M, Lopez S, Suel L, Demignon J, Thornton C, Ozaki H, Kawakami K, Barbet P, Beckmann JS, et al. Six and Eya expression during human somitogenesis and MyoD gene family activation. J Muscle Res Cell Motil 2002;23(3):255-64. 
45. Grifone R, Laclef C, Spitz F, Lopez S, Demignon J, Guidotti JE, Kawakami K, Xu PX, Kelly R, Petrof BJ, et al. Six 1 and Eya1 expression can reprogram adult muscle from the slow-twitch phenotype into the fast-twitch phenotype. Mol Cell Biol 2004;24(14):6253-67. doi: 10.1128/mcb.24.14.6253-6267.2004.

46. Frey N, Barrientos T, Shelton JM, Frank D, Rütten H, Gehring D, Kuhn C, Lutz M, Rothermel B, Bassel-Duby R, et al. Mice lacking calsarcin-1 are sensitized to calcineurin signaling and show accelerated cardiomyopathy in response to pathological biomechanical stress. Nat Med 2004;10:1336. doi: 10.1038/nm1132.

47. Zhang Y, Yu B, He J, Chen D. From Nutrient to MicroRNA: a Novel Insight into Cell Signaling Involved in Skeletal Muscle Development and Disease. Int J Biol Sci 2016;12(10):1247-61. doi: 10.7150/ijbs.16463.

48. Sun Y, Ge Y, Drnevich J, Zhao Y, Band M, Chen J. Mammalian target of rapamycin regulates miRNA-1 and follistatin in skeletal myogenesis. The Journal of cell biology 2010;189(7):1157-69. doi:

10.1083/jcb.200912093.

49. Ye P, Liu Y, Chen C, Tang F, Wu Q, Wang X, Liu C-G, Liu X, Liu R, Liu Y, et al. An mTORC1-Mdm2-Drosha axis for miRNA biogenesis in response to glucose- and amino acid-deprivation. Mol Cell 2015;57(4):708-20. doi: 10.1016/j.molcel.2014.12.034.

\section{Tables}

Table 1 Primer sequences used for quantitative RT-PCR

\begin{tabular}{|lllll|}
\hline Gene & Forward $\left(5^{\prime}\right.$ to $\left.3^{\prime}\right)$ & Reverse $\left(5^{\prime}\right.$ to $\left.3^{\prime}\right)$ & $\begin{array}{l}\text { Product } \\
\text { length } \\
\text { (bp) }\end{array}$ & Locus \\
\hline MyHCl & ACCAACCTGTCCAAGTTCCG & CGCGGCTACTCCTCATTCAA & 143 & XM_018054604.1 \\
\hline MyHCIIA & AAGGGCTGACATTGCTGAGT & TGCCTCTCTTCAGTCATTCCA & 122 & XM_018064659.1 \\
\hline MyHCIIX & GGTCTACGCAAACACGAGAG & GCGGAATTTGGAGAGGTTGAC & 177 & XM_018064657.1 \\
\hline MYF5 & AGACGCCTGAAGAAGGTCAA & CTCCACCTGTTCCCTTAGCA & 150 & NM_001287037.1 \\
\hline MYF6 & CAAGTCAGAGGCCAAGGAAG & TTCTAAGGGCTGCAGGGTAA & 103 & NM_001285602.1 \\
\hline MYOD & TGCAAACGCAAGACGACTAA & CTGGTTTGGGTTGCTAGACG & 126 & XM_018058990.1 \\
\hline MYOG & ACAATCTGCACTCCCTCACC & CATCCTGGCAGACAATCTCA & 106 & NM_001285733.1 \\
\hline EYA1 & CCACTCATGTCCAGCTCAGA & GACTGCGAGGCTGTTAAACC & 137 & XM_013967225.2 \\
\hline SIX1 & CAGTCACCTCGCACTTTGAA & TCCTTCATTTCCCACAGAGG & 160 & XM_018058424.1 \\
\hline MYOZ1 & GGACAGCAATGCCTTATGGT & AACTAAGGGTTCGCTCAGCA & 101 & XM_005699215.3 \\
\hline MYOZ2 & TGCCATGCAGAATGAGAAC & TAGGGACAGCTGTGGTGTTG & 182 & XM_013964451.2 \\
\hline ACTG1 & ATGGCTACTGCTGCGTCGT & TTGAAGGTGGTCTCGTGGAT & 161 & XM_018063603.1 \\
\hline
\end{tabular}

\section{Figures}



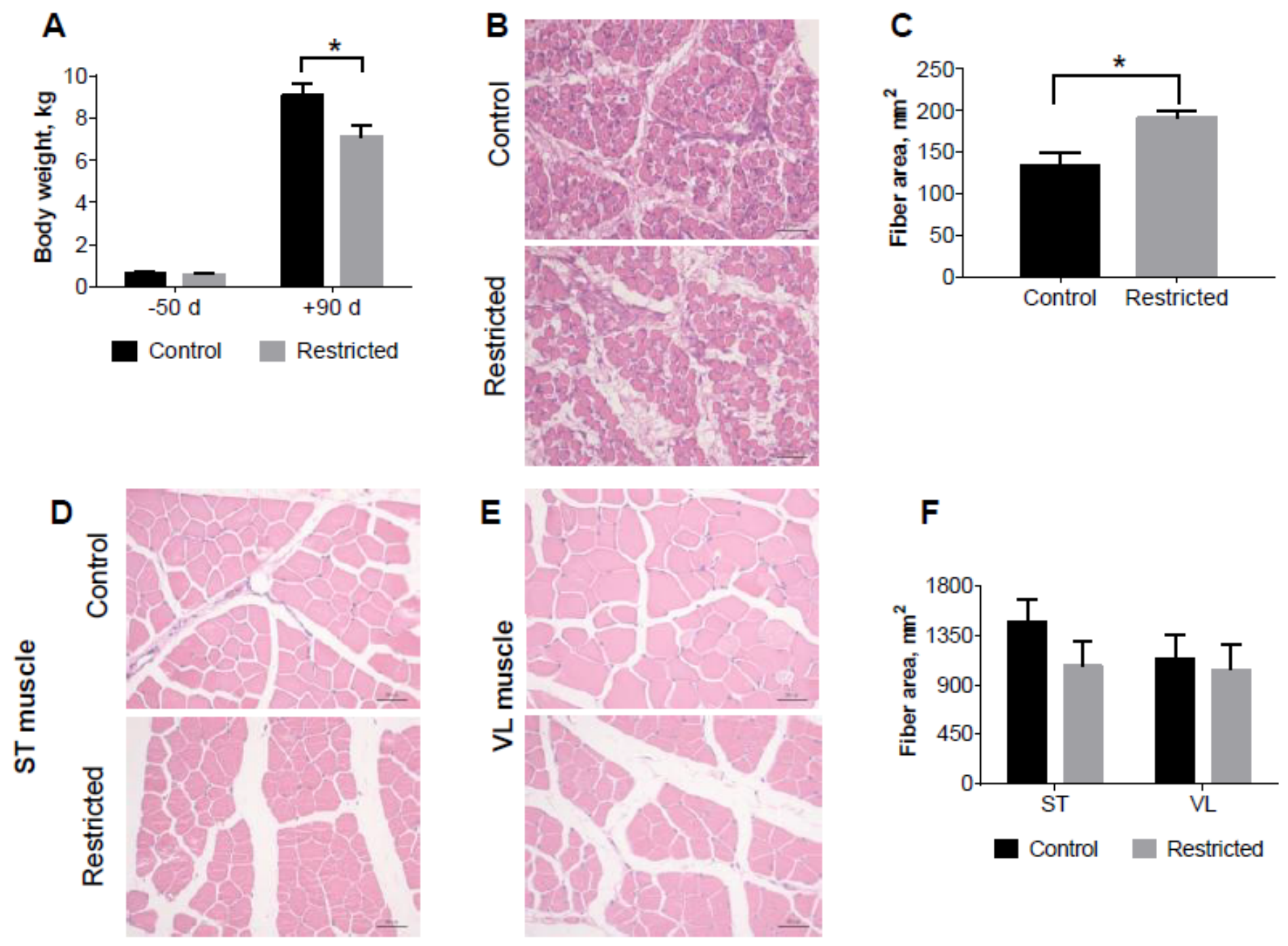

Figure 1

Body weight and area of muscle fibers in offspring. (A) Body weight; Histological section (B) and fiber area (C) of the vastus muscles in fetuses; Histological section of semitendinosus (ST, D) muscles and vastus lateralis $(\mathrm{VL}, \mathrm{E})$ muscles in kids; (F) Fiber areas of ST and VL muscles in kids. * $\mathrm{P}<0.05$. 


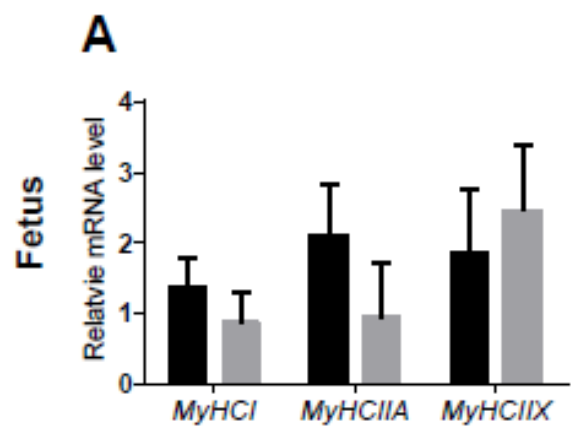

B

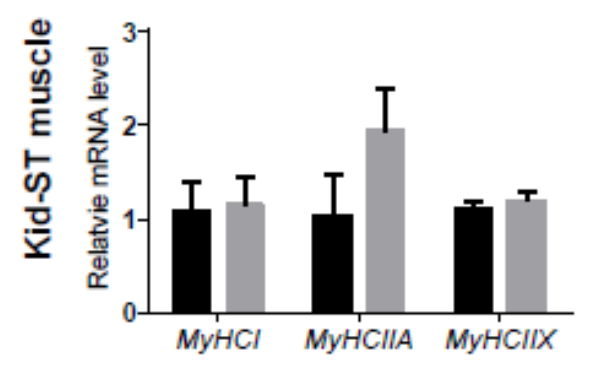

C

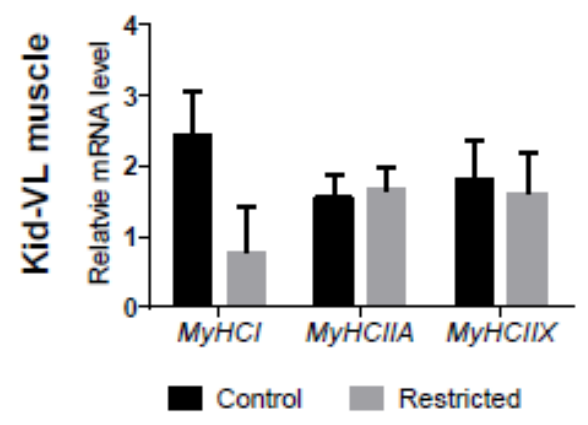

D
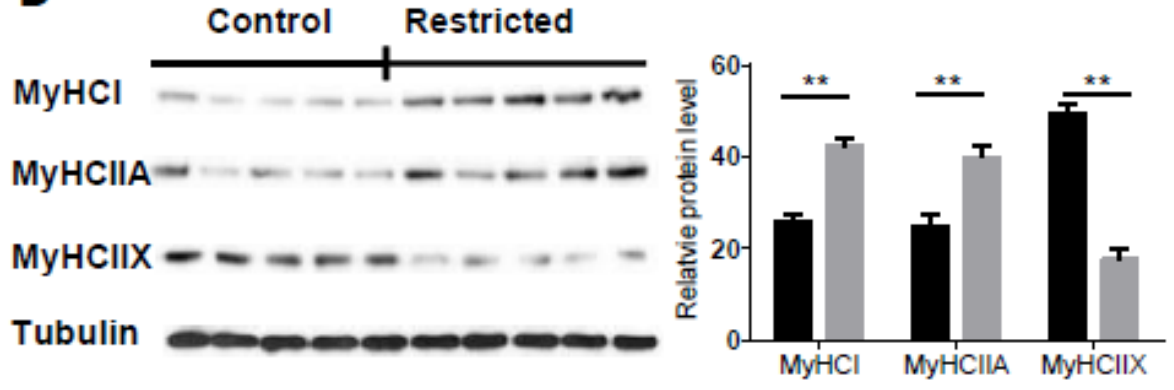

E
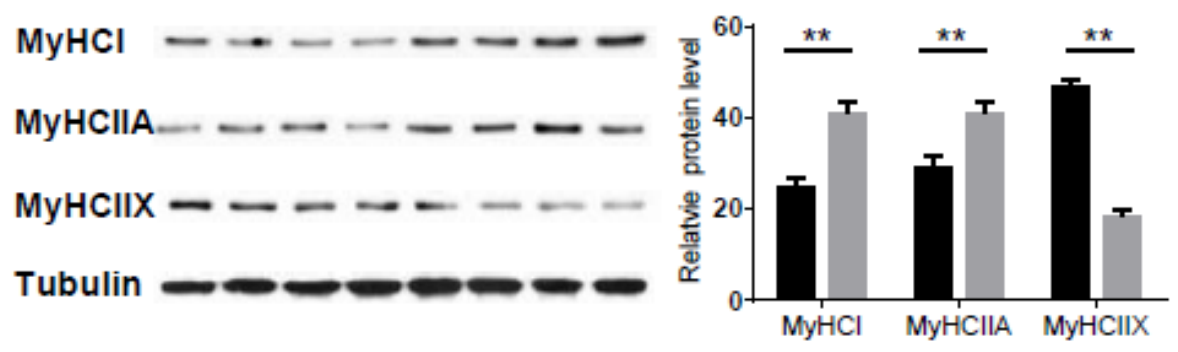

$\mathbf{F}$
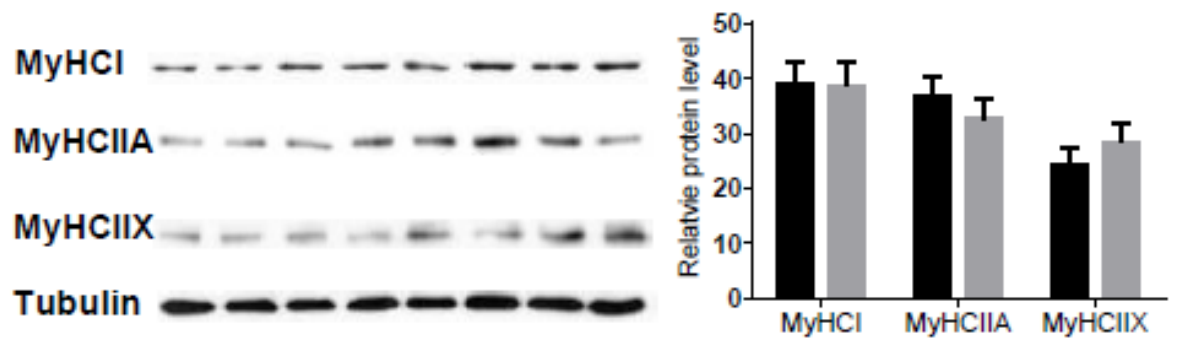

Control Restricted

Figure 2

mRNA and protein expression of myosin heavy chain in offspring. (A) mRNA expression in the vastus muscle of fetuses; mRNA expression in the semitendinosus (ST, B) and vastus lateralis (VL, C) muscles of kids; (D) Protein expression in the vastus muscle of fetuses; Protein expression in the $S T(E)$ and VL $(F)$ muscles in kids. ${ }^{*} \mathrm{P}<$ $0.05 ; * \star P<0.01$. 


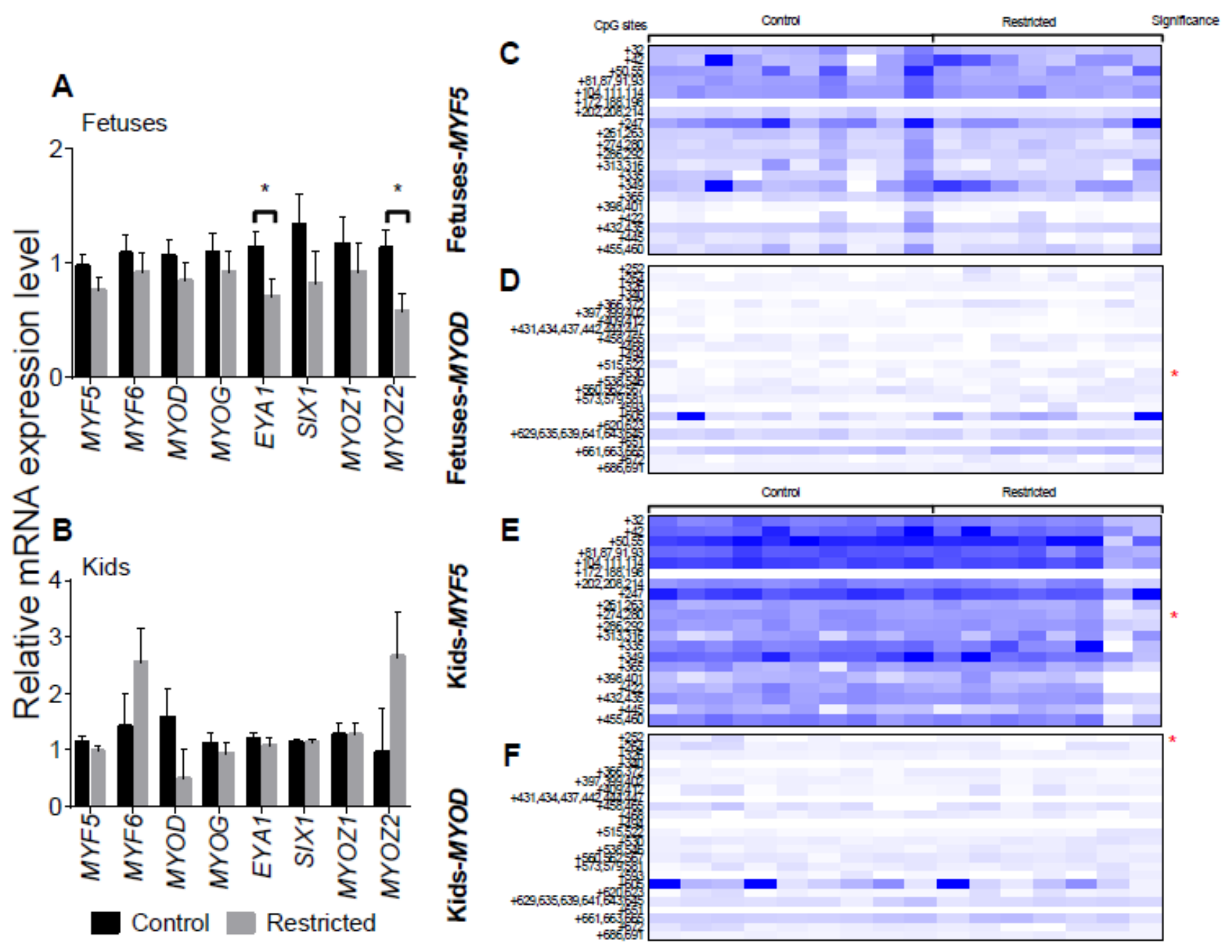

Figure 3

The mRNA expression and DNA methylation of myogenic factors in offspring. (A) mRNA expression in the vastus muscles of fetuses; (B) mRNA expression in the semitendinosus (ST) muscles of kids; (C) MYF5 and (D) MYOD methylation in the vastus muscles of fetuses; (E) MYF5 and (F) MYOD methylation in the semitendinosus (ST) muscles of kids. ${ }^{*} \mathrm{P}<0.05$. 
A Vastus muscle in fetuses

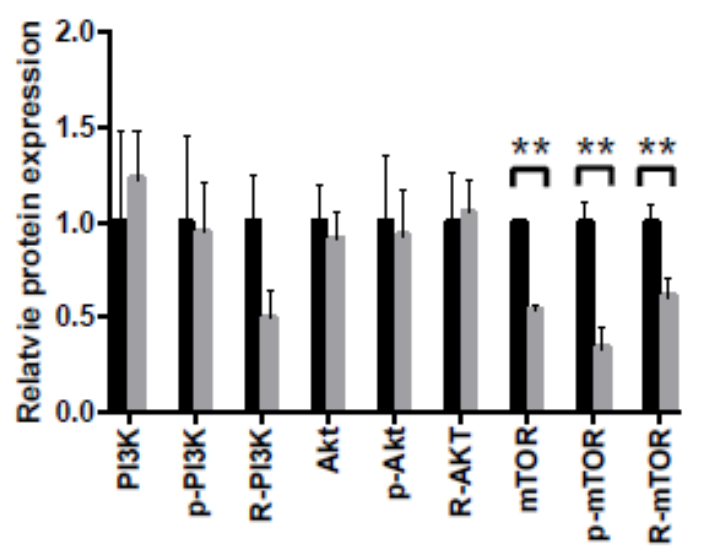

B

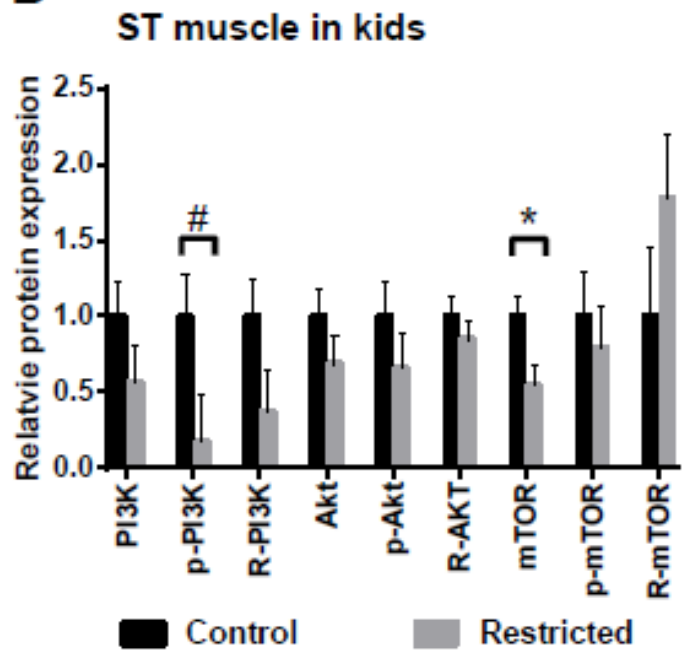

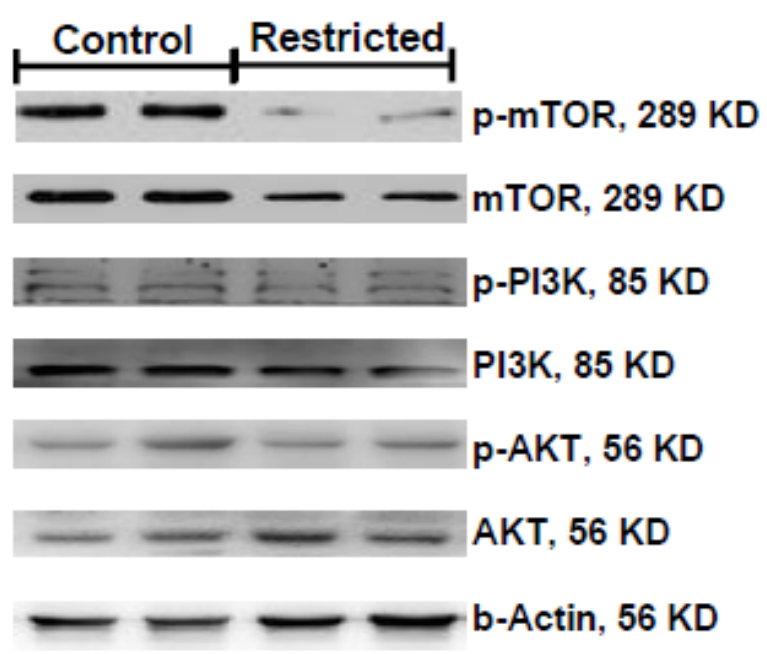

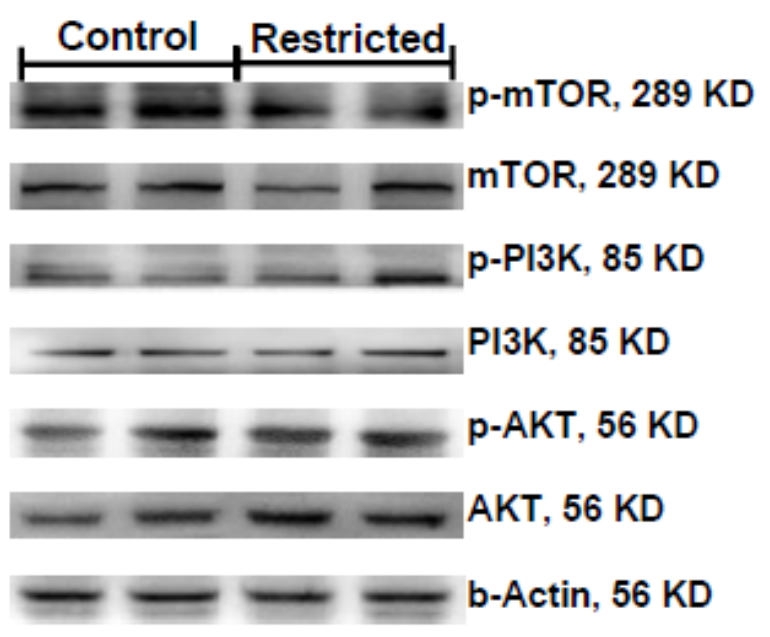

Figure 4

The protein expression of mTOR signaling in the skeletal muscles of offspring. (A) vastus muscles in fetuses;

(B) semitendinosus (ST) muscles in kids. *P $<0.05$; ** $\mathrm{P}<0.01$.

\section{Supplementary Files}

This is a list of supplementary files associated with this preprint. Click to download.

- Additionalfile1.docx 